\title{
A prospective multicenter cohort study of frailty in younger critically ill patients
}

\author{
Sean M. Bagshaw ${ }^{1 *}$, Sumit R. Majumdar ${ }^{2}$, Darryl B. Rolfson ${ }^{3}$, Quazi Ibrahim ${ }^{4}$, Robert C. McDermid ${ }^{5}$ and \\ H. Tom Stelfox ${ }^{6}$
}

\begin{abstract}
Background: Frailty is a multidimensional syndrome characterized by loss of physiologic and cognitive reserve that heightens vulnerability. Frailty has been well described among elderly patients (i.e., 65 years of age or older), but few studies have evaluated frailty in nonelderly patients with critical illness. We aimed to describe the prevalence, correlates, and outcomes associated with frailty among younger critically ill patients.
\end{abstract}

Methods: We conducted a prospective cohort study of 197 consecutive critically ill patients aged 50-64.9 years admitted to intensive care units (ICUs) at six hospitals across Alberta, Canada. Frailty was defined as a score $\geq 5$ on the Clinical Frailty Scale before hospitalization. Multivariable analyses were used to evaluate factors independently associated with frailty before ICU admission and the independent association between frailty and outcome.

Results: In the 197 patients in the study, mean (SD) age was 58.5 (4.1) years, $37 \%$ were female, $73 \%$ had three or more comorbid illnesses, and $28 \%(n=55 ; 95 \% \mathrm{Cl} 22-35)$ were frail. Factors independently associated with frailty included not being completely independent (adjusted OR [aOR] 4.4, $95 \% \mathrm{Cl} 1.8-11.1$ ), connective tissue disease (aOR 6.0, $95 \% \mathrm{Cl}$ 2.1-17.0), and hospitalization within the preceding year ( $\mathrm{aOR} 3.3,95 \% \mathrm{Cl}$ 1.3-8.1). There were no significant differences between frail and nonfrail patients in reason for admission, Acute Physiology and Chronic Health Evaluation II score, preference for life support, or treatment intensity. Younger frail patients did not have significantly longer (median [interquartile range]) hospital stay (26 [9-68] days vs. 19 [10-43] days; $p=0.4$ ), but they had greater 1-year rehospitalization rates (61 \% vs. $40 \% ; p=0.02)$ and higher 1-year mortality (33\% vs. $20 \%$; adjusted HR 1.8, $95 \% \mathrm{Cl} 1.0-3.3 ; p=0.039)$.

Conclusions: Prehospital frailty is common among younger critically ill patients, and in this study it was associated with higher rates of mortality at 1 year and with rehospitalization. Our data suggest that frailty should be considered in younger adults admitted to the ICU, not just in the elderly. Additional research is needed to further characterize frailty in younger critically ill patients, along with the ideal instruments for identification.

Keywords: Frailty, Critical illness, Intensive care unit, Mortality, Quality of life, Health services

\section{Background}

Frailty is a multidimensional syndrome characterized by a decline in physiologic and cognitive homeostatic reserve that increases susceptibility to adverse events and unfavorable outcomes, often following relatively minor stressors [1]. Frailty is causally related to aging, has been conventionally described in elderly populations, and characterizes a common trajectory at the end of life

\footnotetext{
* Correspondence: bagshaw@ualberta.ca

${ }^{1}$ Division of Critical Care Medicine (University of Alberta Hospital), Faculty of Medicine and Dentistry, University of Alberta, 2-124 Clinical Sciences

Building, 8440-112 Street NW, Edmonton, AB T6G 2B7, Canada

Full list of author information is available at the end of the article
}

[2-5]. Frail persons show greater risk for procedural complications, disability, impaired health-related quality of life (HRQoL), hospitalizations, institutionalization, and death [6-10].

Recent data show that frailty is common among patients admitted to intensive care units (ICUs) [11, 12]. Premorbid frailty appears to be an independent (and potentially modifiable) factor associated with less favorable outcomes and greater health services use [13-15]. However, most studies have been focused exclusively on describing frailty among older populations (i.e., $\geq 65$ years of age); in fact, frailty has rarely been considered to occur 
in the nonelderly $[12,14-16]$. The prevalence of frailty in the Canadian general population among persons aged 40-69 years is estimated at $<10 \%$; however, when present, it portends greater health service use and mortality risk [17].

We hypothesized frail patients may have greater susceptibility to developing critical illness and that their risk may be "age-shifted" compared with nonfrail patients of similar chronologic age. Consequently, the prevalence of frailty may be higher than expected for chronologic age among a cohort of younger patients admitted to the ICU [17]. Previously, we performed a prospective multicenter study in a cohort of critically ill patients to describe the association between frailty and outcomes [11]. In this substudy, we aimed to specifically examine the prevalence, correlates, and outcomes associated with frailty in a younger cohort of critically ill patients (i.e., age at ICU admission 50-64.9 years), in whom it has rarely been described.

\section{Methods}

\section{Study design, participants and setting}

We conducted a planned substudy of a prospective multicenter cohort study that has been described previously [11]. Adults admitted to six closed multisystem medical-surgical ICUs located in two tertiary/academic and four community hospitals in Alberta, Canada, between February 2010 and July 2011 were screened for enrollment [11]. The study was approved by the research ethics board at the University of Alberta (Pro00007628). All participants or their designated surrogate decisionmakers provided written informed consent to participate.

\section{Frailty definition}

Frailty was operationalized using the Canadian Study of Health and Aging Clinical Frailty Scale (CFS) score, which was modified to an 8-point tool designed to categorize patients as fit, vulnerable, or frail [6]. The CFS is a subjective judgment-based screening tool for frailty that has been proven to be valid, reliable, and simple to perform. We defined patients as frail if their CFS score was $\geq 5$ (moderate to severe frailty for CFS score 6-8), as vulnerable if their CFS score was 4 , and as fit if their CFS score was $\leq 3$ [11]. Trained coordinators interviewed participants and/or their surrogate decision-makers and reviewed each participant's medical record.

\section{Outcomes}

The primary outcome was all-cause mortality 1 year following enrollment. Secondary outcomes were focused on (1) patient-centered outcomes, including ICU, hospital, 90-day, and 6-month mortality; HRQoL at 6 and at 12 months, captured using the EuroQol (EQ-5D) Health Questionnaire (including the EQ-5D visual analogue scale [EQ-5D-VAS]) [13]; and discharge disposition; and (2) health service use, including ICU and hospital lengths of stay, ICU readmission, and hospital readmission in the 1-year period following enrollment.

\section{Data collection and management}

Data were prospectively captured on standardized forms and entered into an electronic database. These data elements included sociodemographic factors, baseline functional status and disability (e.g., basic and instrumental activities of daily living), comorbid conditions defined and summated using the Elixhauser comorbidity scale [18], prescription medications, source of ICU admission (e.g., ward, operating theater, emergency department), diagnostic category, illness severity (e.g., defined according to the Acute Physiology and Chronic Health Evaluation [APACHE] II score [19]), presence and severity of organ dysfunction (e.g., defined according to the Sequential Organ Failure Assessment score [20]), treatment intensity (e.g., mechanical ventilation, vasoactive support, renal replacement therapy), and preferences for life-sustaining therapy (e.g., full ICU support, limitation in therapy). Participants were contacted at 6 and 12 months to ascertain long-term outcomes, including vital status, disposition, and HRQoL.

\section{Statistical analyses}

Among nonelderly patients, the distribution of CFS scores was presented and descriptive statistics were calculated according to the presence or absence of frailty. Independent associations between baseline sociodemographic and clinical characteristics as well as frailty status were evaluated using multivariable logistic regression analysis. Clinically important variables (i.e., sex, comorbidity, case mix, APACHE II score, site) and those found to be significant in univariate analysis $(p=0.20)$ were entered into the multivariable model. Model calibration and discrimination were assessed using the Hosmer-Lemeshow goodness-offit test, Brier score, and the AUC (c-statistic). The independent percentage contribution of each variable in the model's explanatory power was estimated by dividing differences in log-likelihoods of the nested models by the difference in the log-likelihoods of null and full (final) models $[14,21]$. Sensitivity analysis was performed by adding the variables age, surgical status, and sepsis to the multivariable model. Survival curves were plotted using Kaplan-Meier curves with log-rank tests. Multivariable Cox proportional hazards regression analyses were performed to analyze survival. Similar to the analyses described above, clinically important variables (i.e., sex, comorbidity, case mix, APACHE II score, site) and those found to be significant in univariate analysis $(p=0.20)$ were entered into the multivariable model. Proportional hazards model assumptions were checked by comparing 
$\log (-\log )$ plots of survival probabilities over time of frail and nonfrail patients and testing interactions between frailty status and logarithmic scales of follow-up times in the model. A $p$ value $<0.05$ was considered statistically significant for all comparisons. All analyses were performed using STATA 12.1 software (StataCorp, College Station, TX, USA).

\section{Results}

Overall, 197 patients (47\% of the study cohort) aged 50-64.9 years were included in this substudy (Additional files 1 and 2). The mean (SD) age was 58.5 (4.1) years, $37 \%(n=72)$ were female, $73 \%(n=143)$ had three or more comorbid illnesses, $74 \%(n=146)$ were living at home independently, and $41 \%(n=$ 80) had been hospitalized in the preceding 1-year period. The median (interquartile range) prehospital CFS score was $4(3-5)$. Of the cohort, $39 \%$ (95\% CI $32-46 ; n=76)$ were classified as fit, $34 \%$ (95\% CI $27-41 \% ; n=66)$ were classified as vulnerable, and $28 \%$ (95\% CI 22-35\%; $n=55)$ were classified as frail (CFS score $\geq 5$ ) (Fig. 1).

Factors associated with frailty among nonelderly patients There were numerous differences in baseline sociodemographic and clinical characteristics among frail and nonfrail patients (Table 1). Several factors were found in multivariable analysis to be independently associated with prehospital frailty, including prehospital residence, receipt of disability insurance, prior hospitalization, female sex, and comorbid connective tissue disease (CTD) (Table 2). These five variables represented $89 \%$ of the final model's explanatory power for prehospital frailty.

\section{Association between frailty and clinical course among nonelderly patients}

Other than postoperative status (which was less common among frail patients), there were no significant differences in diagnostic category, admission source, treatment intensity or patient preferences for lifesustaining therapy between frail and not frail (Table 3).

\section{Association between frailty and mortality among nonelderly patients}

Unadjusted mortality at 1 year was not significantly greater for frail patients than for nonfrail patients (32.7\% vs. $20.4 \%$; OR 1.90, $95 \%$ CI 0.95-3.78). Unadjusted mortality in the ICU, in the hospital, at 90 days, and at 6 months was similarly not statistically different between frail and nonfrail patients (Table 3). In multivariable analysis, frail patients were found to have a higher adjusted risk of death at 1 year than nonfrail patients (adjusted HR 1.83, $95 \%$ CI 1.03-3.25; $p=0.039$ ) (Fig. 2 and Fig. 3). The burden of comorbid illness, acute illness severity, and frailty represented $81 \%$ of the model's final explanatory power for 1-year mortality. There was evidence of a dose-response increase in adjusted risk of death associated with greater CFS score (Table 4 and Fig. 4). This increase was most apparent when we compared fit (CFS score 1-3) with moderate to severe frailty (CFS score 6-8), while there was overlap among those classified as vulnerable (CFS score 4) and mildly frail (CFS score 5). In an exploratory analysis using the entire study cohort $(n=421)$, there was an effect modification between frailty and age with respect to all-cause mortality (mortality among frail patients age $<65$ years $36 \%$ vs. age $\geq 65$ years $59 \%$; OR 2.0,3 $95 \%$ CI 1.30-3.16; $p<0.001)$,

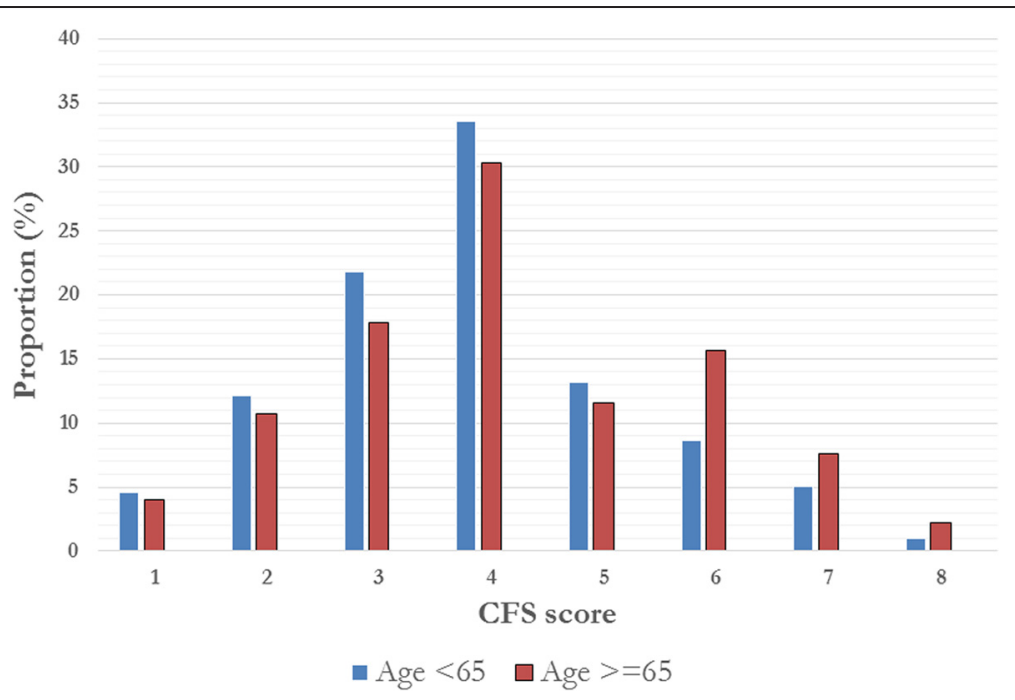

Fig. 1 Summary of prevalence of Clinical Frailty Scale (CFS) scores, stratified by age older or younger than 65 years 
Table 1 Baseline sociodemographic, clinical, and comorbidity data for patients younger than 65 years old admitted to the intensive care unit, stratified by frailty status

\begin{tabular}{|c|c|c|c|}
\hline Variable & $\begin{array}{l}\text { Frail } \\
(n=55, \\
28 \%)\end{array}$ & $\begin{array}{l}\text { Nonfrail } \\
(n=142, \\
72 \%)\end{array}$ & $p$ Value \\
\hline Age, years, mean $\pm S D$ & $58.9 \pm 4.1$ & $58.4 \pm 4.2$ & 0.444 \\
\hline Sex, female, $n(\%)$ & $28(50.9)$ & $44(31.0)$ & 0.009 \\
\hline Widowed, $n$ (\%) & $4(7.3)$ & $7(4.9)$ & 0.504 \\
\hline Education, $n$ (\%) & & & 0.039 \\
\hline Less than secondary school & $14(25.5)$ & $17(12.0)$ & \\
\hline Secondary school & $23(41.8)$ & $58(40.8)$ & \\
\hline Higher-level degree & $18(32.7)$ & $67(47.2)$ & \\
\hline \multicolumn{4}{|l|}{ Employment status, $n$ (\%) } \\
\hline Full-time & $9(16.4)$ & $50(35.2)$ & 0.010 \\
\hline Part-time & $1(1.8)$ & 15 (10.6) & 0.045 \\
\hline On disability & $28(50.9)$ & $31(21.8)$ & $<0.001$ \\
\hline Prehospital residence, $n(\%)$ & & & $<0.001$ \\
\hline At home (independent) & $23(41.8)$ & $123(86.6)$ & \\
\hline At home (with help) & $26(47.3)$ & $18(12.7)$ & \\
\hline Other & $6(10.9)$ & $1(0.7)$ & \\
\hline \multicolumn{4}{|l|}{ CSHA Function Scale score $(n, \%)$} \\
\hline Eating (independent) & $51(92.7)$ & $142(100)$ & 0.006 \\
\hline Dressing (independent) & $47(85.5)$ & $141(99.3)$ & $<0.001$ \\
\hline Personal care (independent) & $45(81.8)$ & $142(100)$ & $<0.001$ \\
\hline Walking (independent) & $35(63.6)$ & $134(94.4)$ & $<0.001$ \\
\hline Getting out of bed (independent) & $40(72.7)$ & $141(99.3)$ & $<0.001$ \\
\hline Taking bath (independent) & $37(67.3)$ & $140(98.6)$ & $<0.001$ \\
\hline Using toilet (independent) & $49(89.1)$ & $140(98.6)$ & 0.007 \\
\hline Using telephone (independent) & $52(94.5)$ & $142(100)$ & 0.021 \\
\hline Going shopping (independent) & $25(45.5)$ & $133(93.7)$ & $<0.001$ \\
\hline Preparing own meals (independent) & $29(52.7)$ & $138(97.2)$ & $<0.001$ \\
\hline Doing housework (independent) & $26(47.3)$ & $132(93.0)$ & $<0.001$ \\
\hline Taking medicine (independent) & $40(72.7)$ & $133(93.7)$ & $<0.001$ \\
\hline Managing own finances (independent) & $46(83.6)$ & $138(97.2)$ & 0.002 \\
\hline Elixhauser comorbidity score, mean \pm SD & $8.7 \pm 9.1$ & $6.6 \pm 7.6$ & 0.098 \\
\hline Hypertension & $26(47.3)$ & $73(51.4)$ & 0.602 \\
\hline Heart failure & $10(18.2)$ & $9(6.3)$ & 0.012 \\
\hline Diabetes mellitus & $18(32.7)$ & $31(21.8)$ & 0.112 \\
\hline Chronic kidney disease & $13(23.6)$ & $23(16.2)$ & 0.225 \\
\hline Rheumatoid/connective tissue disease & $20(36.4)$ & $13(9.2)$ & $<0.001$ \\
\hline Any cancer & $5(9.1)$ & $16(11.3)$ & 0.657 \\
\hline Alcohol/drug abuse & $16(29.1)$ & $50(35.2)$ & 0.414 \\
\hline Psychosis & $3(5.5)$ & $4(2.8)$ & 0.401 \\
\hline Depression & $18(32.7)$ & $38(26.8)$ & 0.405 \\
\hline Prescription medications, $n$, mean $\pm S D$ & $8.8 \pm 6.2$ & $5.1 \pm 4.3$ & $<0.001$ \\
\hline $\begin{array}{l}\text { Hospitalization in preceding } \\
1 \text {-year period, mean } \pm S D\end{array}$ & $34(61.8)$ & $46(32.4)$ & $<0.001$ \\
\hline
\end{tabular}

CSHA Canadian Study on Health and Aging
Table 2 Multivariable analysis of factors associated with prehospital frailty among patients younger than 65 years old

\begin{tabular}{|c|c|c|c|}
\hline Variable & $\begin{array}{l}\text { Adjusted OR } \\
(95 \% \mathrm{Cl})\end{array}$ & $p$ Value & $\%$ contribution \\
\hline Sex & & & 3.8 \\
\hline Male & 1 & & \\
\hline Female & $2.01(0.87-4.66)$ & 0.103 & \\
\hline $\begin{array}{l}\text { Elixhauser comorbidity score, } \\
\text { mean } \pm \text { SD }\end{array}$ & $0.96(0.91-1.02)$ & 0.213 & 1.6 \\
\hline Rheumatoid/CTD & $6.00(2.12-17.0)$ & 0.001 & 19.7 \\
\hline Heart failure & $3.28(0.78-13.7)$ & 0.104 & 1.8 \\
\hline Prehospital residence & & & 49.3 \\
\hline At home (independent) & 1 & & \\
\hline At home (with help)/other & $4.40(1.75-11.1)$ & 0.002 & \\
\hline On disability & $2.11(0.83-5.35)$ & 0.117 & 4.1 \\
\hline $\begin{array}{l}\text { Managing own finances } \\
\text { (independent) }\end{array}$ & $0.24(0.05-1.24)$ & 0.088 & 3.5 \\
\hline Never married & $0.23(0.03-1.56)$ & 0.133 & 2.8 \\
\hline Education & & & 1.7 \\
\hline Less than high school & 1 & & \\
\hline High school & $0.76(0.23-2.50)$ & 0.653 & \\
\hline Higher-level degree & $0.53(0.16-1.75)$ & 0.296 & \\
\hline $\begin{array}{l}\text { Prescription medications, } n \text {, } \\
\text { mean } \pm S D\end{array}$ & $1.01(0.93-1.10)$ & 0.748 & 0.1 \\
\hline Prior hospitalization & $3.29(1.34-8.10)$ & 0.010 & 11.7 \\
\hline
\end{tabular}

CTD connective tissue disease

The overall model is significant (likelihood ratio $x_{12}^{2}=78.73$ with $p<0.0001$ ) with good discriminatory ability (c-statistic 0.85 ) and goodness of fit (calibration, Brier score 0.12; Hosmer-Lemeshow $X_{8}^{2}=10.37$ with $p=0.24$ ). In sensitivity analyses, age, surgical status, and sepsis were also included in the multivariable model. These did not translate into significant changes across any covariates or percentage contribution to the model.

although in multivariable analysis the interaction term was not statistically significant (OR $0.84,95 \%$ CI $0.42-$ $1.71 ; p=0.68$ ) (Additional file 3).

\section{Association between frailty and nonfatal outcomes among nonelderly patients}

Among hospital survivors, $69.8 \%$ of frail and $76.2 \%$ of nonfrail patients were living at home (difference $6.4 \%$, $95 \%$ CI $-9.9 \%$ to $22.1 \%$ ); however, only $32.8 \%$ of frail patients were independent (absolute decrease from prehospital level $-9.2 \%, 95 \%$ CI $-28.4 \%$ to $9.9 \%$ ), while $50.8 \%$ of nonfrail patients were independent (absolute decrease from prehospital $-35.8 \%, 95 \% \mathrm{CI}$ $-46.3 \%$ to $-25.3 \%$ ) at the time of hospital discharge. EQ-5D-VAS scores were similar for frail and nonfrail patients at 6 months (58.8 [18.7] vs. 63.4 [20.4]; $p=0.25)$ and at 12 months (63.0 [20.2] vs. 68.3 [17.6]; $p=0.18$ ). There was no significant difference between 6 and 12 months in the EQ-5D-VAS for frail and nonfrail patients (4.0 [95 \% CI -1.4 to 9.5] vs. 5.3 [95 \% CI $1.8-$ 8.8 ]; $p=0.72$ ) or in the proportion achieving a minimal 
Table 3 Summary of case mix, clinical course, and outcomes for critically ill patients younger than 65 years old, stratified by frailty status

\begin{tabular}{|c|c|c|c|}
\hline Variable & Frail & Nonfrail & $p$ Value \\
\hline $\begin{array}{l}\text { ICU diagnostic category, } \\
n(\%)\end{array}$ & & & 0.284 \\
\hline Sepsis & $10(18.2)$ & 15 (10.6) & \\
\hline Cardiovascular & $5(9.1)$ & $20(14.1)$ & \\
\hline Respiratory & $22(40.0)$ & $45(31.7)$ & \\
\hline Gastrointestinal/liver & $9(16.4)$ & 25 (17.6) & \\
\hline Other $^{\mathrm{a}}$ & $9(16.4)$ & $37(26.1)$ & \\
\hline ICU admission source, $n$ (\%) & & & 0.900 \\
\hline Ward transfer & $17(30.9)$ & $41(28.9)$ & \\
\hline OR theater transfer & $13(23.6)$ & $39(27.5)$ & \\
\hline ED & $14(25.5)$ & $40(28.1)$ & \\
\hline Other ${ }^{b}$ & $10(18.2), 1(1.8)$ & $20(14.1), 2(1.4)$ & \\
\hline Postoperative, n (\%) & $13(23.6)$ & $55(38.7)$ & 0.046 \\
\hline APACHE II score, mean \pm SD & $19.8 \pm 6.7$ & $17.9 \pm 7.4$ & 0.103 \\
\hline SOFA score, mean \pm SD & $8.2 \pm 4.0$ & $7.0 \pm 4.1$ & 0.086 \\
\hline Mechanical ventilation, $n(\%)$ & $52(94.5)$ & $120(84.5)$ & 0.058 \\
\hline Vasoactive medications, $n$ (\%) & $33(60.0)$ & $72(50.7)$ & 0.241 \\
\hline $\begin{array}{l}\text { Renal replacement therapy, } \\
n(\%)\end{array}$ & $6(10.9)$ & $21(14.8)$ & 0.478 \\
\hline Preferences for support, $n$ (\%) & & & 0.069 \\
\hline Full ICU support & $48(87.3)$ & $134(95.0)$ & \\
\hline $\begin{array}{l}\text { Limitations on therapy } \\
\text { (DNR order) }\end{array}$ & $7(12.7)$ & $7(5.0)$ & \\
\hline \multicolumn{4}{|l|}{ Mortality, n (\%) } \\
\hline ICU & $6(10.9)$ & $10(7.0)$ & 0.390 \\
\hline Hospital & $11(20.0)$ & $20(14.1)$ & 0.306 \\
\hline 90-day & $13(23.6)$ & $21(14.8)$ & 0.140 \\
\hline 6-month & $16(29.1)$ & $25(17.6)$ & 0.075 \\
\hline 1-year & $18(32.7)$ & $29(20.4)$ & 0.069 \\
\hline $\begin{array}{l}\text { ICU length of stay, days, } \\
\text { median (IQR) }\end{array}$ & $6(3.5-11.5)$ & $6(3-10)$ & 0.383 \\
\hline ICU readmission, $n$ (\%) & $9(18.4)$ & $18(13.6)$ & 0.427 \\
\hline $\begin{array}{l}\text { Hospital length of stay, } \\
\text { median (IQR) }\end{array}$ & $26(9-68)$ & $18.5(10-43)$ & 0.389 \\
\hline Hospital readmission, $n(\%)$ & $26(60.5)$ & $49(40.2)$ & 0.022 \\
\hline Discharge disposition, $n$ (\%) & & & 0.112 \\
\hline Living at home independent & $14(32.6)$ & $62(50.8)$ & \\
\hline Living at home with help & $16(37.2)$ & $31(25.4)$ & \\
\hline Other & $13(30.2)$ & $29(23.8)$ & \\
\hline \multicolumn{4}{|l|}{ EQ-5D-VAS, 6-month } \\
\hline Mean (SD) & $58.8(18.7)$ & $63.4(20.4)$ & 0.254 \\
\hline$n(\%)$ & $34 / 39(87.2)$ & $96 / 117(82.1)$ & \\
\hline
\end{tabular}

Table 3 Summary of case mix, clinical course, and outcomes for critically ill patients younger than 65 years old, stratified by frailty status (Continued)

\begin{tabular}{|c|c|c|c|}
\hline \multicolumn{4}{|l|}{ EQ-5D-VAS, 1-year } \\
\hline Mean (SD) & $63.0(20.2)$ & $68.3(17.6)$ & 0.184 \\
\hline$n(\%)$ & 28/37 (75.7) & 85/113 (75.2) & \\
\hline $\begin{array}{l}\text { MCIDC in EQ-5D-VAS } \\
\text { between } 6 \text { and } 12 \text { months, } \\
n(\%)\end{array}$ & 10/27 (37.0) & 29/77 (37.7) & 0.95 \\
\hline \multicolumn{4}{|l|}{ EQ-5D, 6-month, $n(\%)$} \\
\hline Mobility & $25(71.4)$ & $40(41.2)$ & 0.002 \\
\hline Self-care & $11(31.4)$ & $8(8.2)$ & 0.001 \\
\hline Usual activities & $30(85.7)$ & $65(67.7)$ & 0.041 \\
\hline Pain/discomfort & $30(85.7)$ & $54(55.7)$ & 0.002 \\
\hline Anxiety/depression & $19(54.3)$ & $36(37.1)$ & 0.077 \\
\hline \multicolumn{4}{|c|}{$\begin{array}{l}\text { ICU intensive care unit, } E D \text { emergency department, } O R \text { operating room, VAS } \\
\text { visual analogue scale, DNR do not resuscitate, } A P A C H E \text { Acute Physiology and } \\
\text { Chronic Health Evaluation, SOFA Sequential Organ Failure Assessment, EQ-5D } \\
\text { EuroQol Health Questionnaire, MCID minimal clinically important difference, } \\
\text { IQR interquartile range } \\
\text { aOther was defined as urologic/renal, neurologic, endocrinologic/metabolic, } \\
\text { hematologic/oncologic, trauma, musculoskeletal } \\
\text { bOther was defined as transfer from another hospital, other location } \\
\text { 'Minimum difference of } 7 \text { points in the EQ-5D-VAS was considered clinically } \\
\text { important [13] }\end{array}$} \\
\hline
\end{tabular}

clinically important improvement in EQ-5D-VAS (37.0 \% vs. $37.7 \% ; p=0.95)$ by 12 months. A greater proportion of frail patients had problems across all EQ-5D domains compared with those who were not frail (Table 3).

\section{Association between frailty and health services use among nonelderly patients}

There were no statistical differences in ICU or hospital lengths of stay or rates of ICU readmission between frail and nonfrail patients (Table 3). The hospital readmission rate in the year following enrollment was significantly greater for frail patients than for nonfrail patients.

\section{Discussion}

We performed a planned subgroup study to describe the prevalence, as well as to characterize the correlates and outcomes associated with frailty among a younger cohort of critically ill patients. Frailty has customarily been described only among older persons; however, we believe our study provides new knowledge and novel insights into the occurrence and impact of frailty among younger critically ill patients.

\section{Main findings}

First, we showed that frailty was relatively common among younger patients admitted to the ICU in our study, evident in more than one in four. This was significantly greater than the estimated prevalence of frailty 


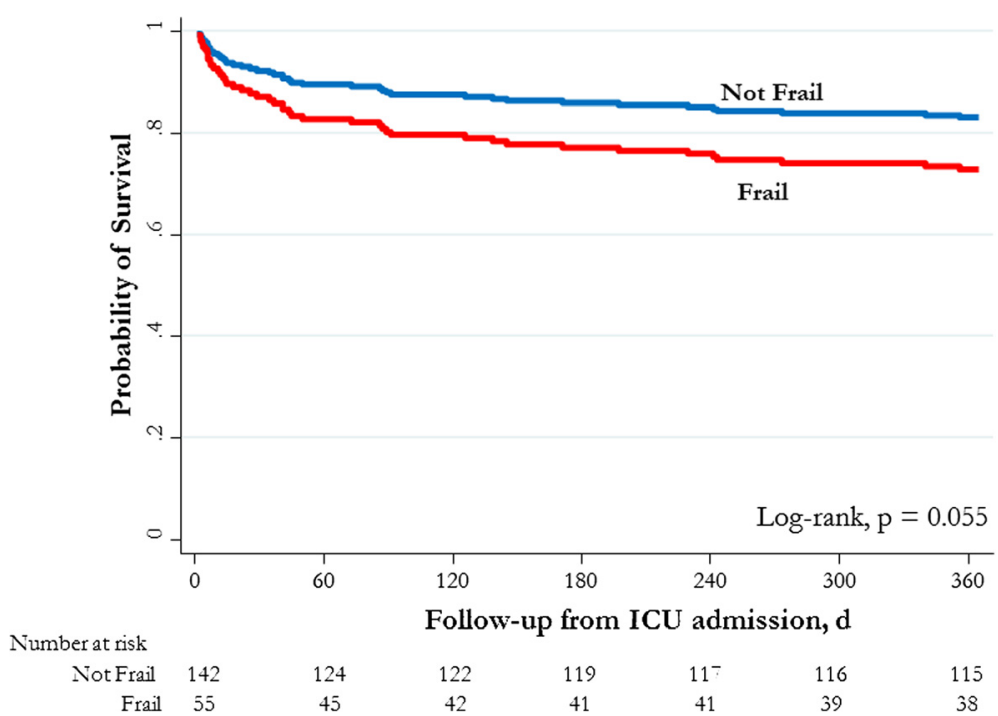

Fig. 2 Adjusted survival probabilities by frailty status in intensive care unit (ICU) patients younger than 65 years old. Survival curves adjusted for sex, Elixhauser comorbidity score, Acute Physiology and Chronic Health Evaluation II score, primary diagnostic criteria, and hospital type (tertiary care/academic vs. community hospital)

among a contemporaneous general population [17]. Second, as expected, several sociodemographic factors correlated with prehospital frailty. Frailty was more common among women, those with less than a secondary school education, those receiving disability insurance, and those requiring assistance at home. In addition, in the 1-year period before the study, health service use was higher among those classified as frail than among those who were not frail. Third, frail patients in this younger cohort where characterized by a high burden of comorbid disease, in particular CTD and heart failure (HF), and were prescribed a greater number of medications than those who were not frail. Fourth, preferences for life support, reasons for ICU admission, and treatment intensity were similar between frail and nonfrail patients. Finally, in adjusted analyses, long-term mortality and rehospitalization were greater among those with prehospital frailty.

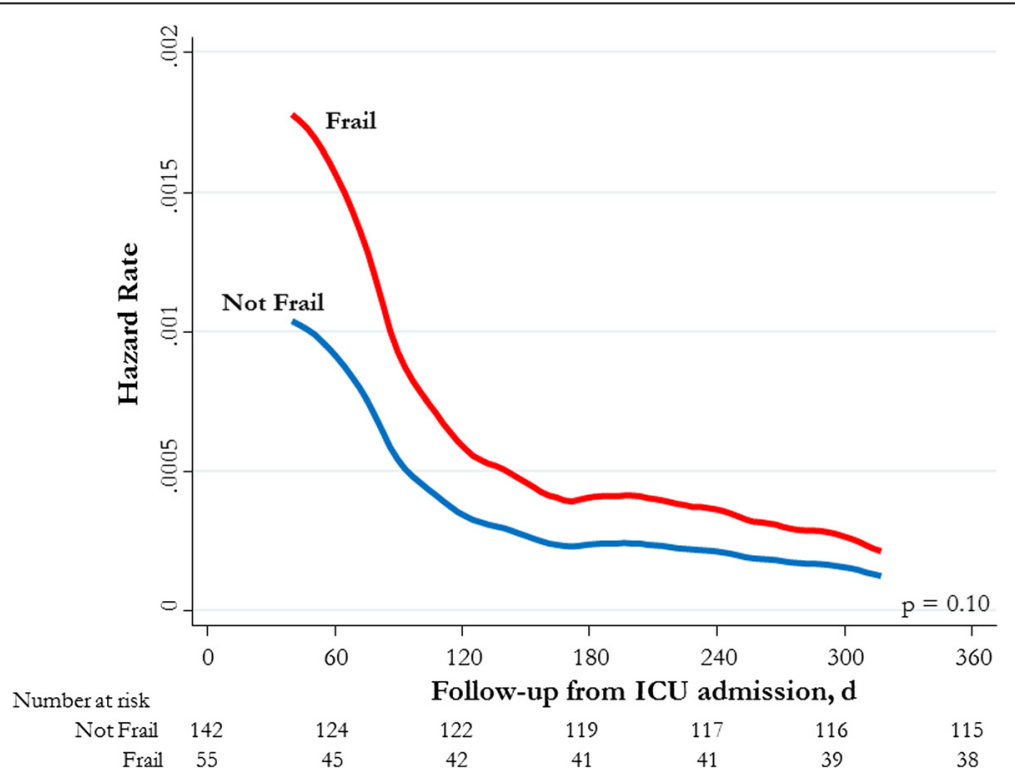

Fig. 3 Adjusted hazard rates of death stratified by frailty status in intensive care unit (ICU) patients younger than 65 years old. Survival curves adjusted for sex, Elixhauser comorbidity score, Acute Physiology and Chronic Health Evaluation II score, primary diagnostic criteria, and hospital type (tertiary care/academic v. community hospital) 
Table 4 Crude and adjusted HR for death by Clinical Frailty Scale score categories in patients younger than 65 years old

\begin{tabular}{|c|c|c|c|c|c|c|}
\hline CFS category & Unadjusted HR & $95 \% \mathrm{Cl}$ & $p$ Value & Adjusted $\mathrm{HR}^{\mathrm{a}}$ & $95 \% \mathrm{Cl}$ & $p$ Value \\
\hline Fit (CFS score 1-3) & 1.0 & - & - & 1.0 & - & - \\
\hline Vulnerable (CFS score 4) & 3.67 & $1.55-8.69$ & 0.003 & 2.89 & $1.19-7.02$ & 0.019 \\
\hline Mild frailty (CFS score 5) & 2.82 & $0.95-8.38$ & 0.063 & 2.54 & $0.82-7.90$ & 0.107 \\
\hline Moderate to severe frailty (CFS score 6-8) & 4.93 & $1.91-12.73$ & 0.001 & 4.41 & $1.62-12.06$ & 0.004 \\
\hline
\end{tabular}

CFS Clinical Frailty Scale

${ }^{a}$ Adjusted by sex, Elixhauser comorbidity score, Acute Physiology and Chronic Health Evaluation II score, primary diagnostic criteria, and hospital type (tertiary care/academic vs. community hospital)

\section{Context with prior literature}

Most published literature is focused on describing frailty among older persons [12, 14, 15]; few authors have characterized its epidemiology among nonelderly persons [17], in particular in the context of critical illness [22]. This is likely attributable to most frailty research being performed in the domain of geriatric medicine $[6,16]$ and using administrative databases with age thresholds (e.g., U.S. Medicare beneficiaries database) [14, 15] or being based on the misconception that frailty is solely a product of chronologic aging [12]. More recently, researchers in a number of studies have evaluated the prevalence and impact of frailty among specialized cohorts of much younger patients, including lung transplant candidates (median age 59 years [23]), end-stage liver disease (mean age 55 years [24]), end-stage kidney disease (mean age 55 years [25]), and kidney transplant (mean age 53 years [26]). A greater rate of deficit accumulation in selected younger persons may accelerate the development of frailty, and, as such, these persons may have "age-shifted" vulnerability to major stressors (i.e., critical illness) [27]. These patients manifest frailty and "age" more rapidly relative to chronologic age [28]. Similarly, the probability of survival after critical illness appears higher for younger than for older frail patients [11]; however, younger patients may still experience a longer and/or more complex post-ICU course and recovery [29-32]. Accruing evidence, along with our data, suggests that selected younger patients, such as those with advanced chronic inflammatory diseases (e.g., CTD) or end-stage organ diseases (e.g., HF, cirrhosis) may benefit from screening for frailty.

Comorbid disease and frailty are not mutually exclusive and may show greater correlation among younger patients with significant and/or advanced chronic illness [1]. As examples, we identified both CTD and HF as predictors of prehospital frailty. Few studies have evaluated the prevalence and impact of frailty among patients with CTD [33]. Numerous factors may predispose these patients to frailty, including chronic disease progression and persistent inflammation, disease-specific therapy (i.e., immunosuppressive or other disease-modifying

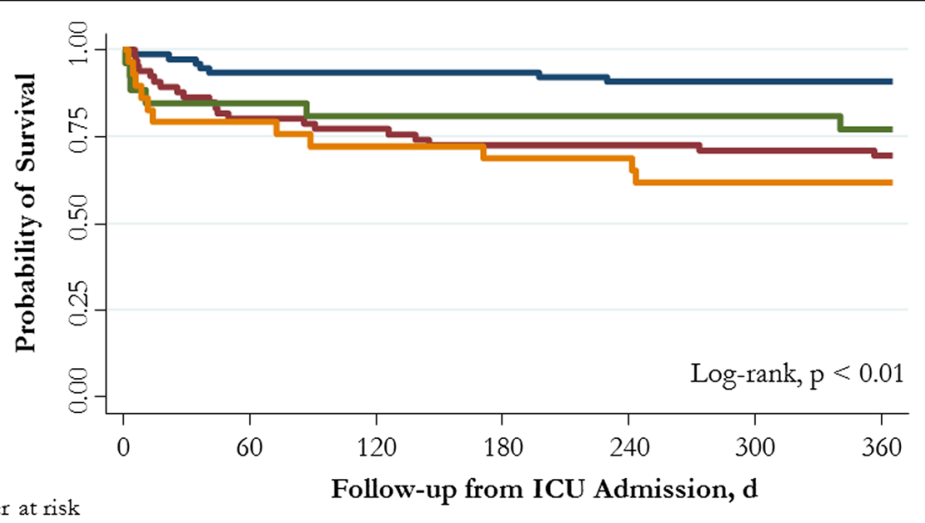

Number at risk

CFS 1-3 76

CFS $4 \quad 66$

CFS $5 \quad 26$

CFS 6-8 29

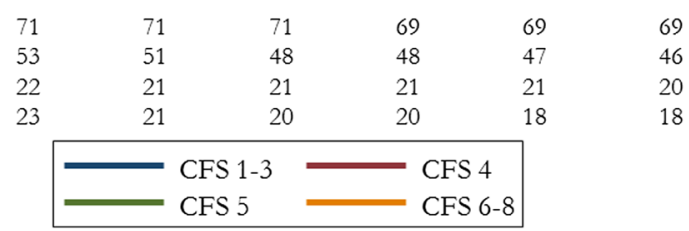

Fig. 4 Kaplan-Meier survival curves stratified by Clinical Frailty Scale (CFS) score categories (fit, vulnerable, frail, moderate to severe frailty) in intensive care unit (ICU) patients younger than 65 years old 
antirheumatic drugs), nutritional alterations (i.e., cachexia), and sarcopenia [34]. Indeed, sarcopenia and nutritional deficiencies before critical illness may amplify early skeletal muscle loss in critical illness, further prolonging recovery and exacerbating risk of incident or worsening disability [35, 36]. Likewise, an estimated 18$54 \%$ of patients with HF are clinically frail [37]. Frailty in HF may have important prognostic implications, including reduced likelihood of self-management, impaired HRQoL, greater hospitalizations, being declined for transplant, and death [37, 38]. We believe our finding of associations between frailty, selected comorbid conditions, and critical illness requires confirmation and evaluation in larger studies.

Prehospital frailty portends a greater risk of death and impaired recovery following the stress of critical illness. This finding would appear robust regardless of age; however, there is likely some additive effect between frailty, older age, and risk of death [11, 12, 16]. Our study suggests that the association between frailty and mortality may be attenuated in younger compared with older patients; however, those with moderate to severe frailty still exhibit significantly higher risk [11]. This implies that frailty among younger patients may be less likely a terminal event or imminent end-of-life trajectory. That said, these relatively young frail survivors have greater opportunity and time at risk for the multifarious physical (i.e., disability) and psychosocial (i.e., depression, posttraumatic stress, impaired HRQoL, inability to work, lost income, social isolation) complications increasingly described after critical illness [29-32, 39]. Indeed, at 6 months, frail survivors in our study described far greater problems with mobility, self-care, usual activities, and pain. We found that more than half of frail survivors described issues with depression and/or anxiety [40]. Interestingly, despite all EQ-5D domains being generally worse among frail patients, EQ-5DVAS scores, while impaired, were not significantly different at 6 and 12 months between frail and nonfrail patients. Thus, frail survivors' self-rated global HRQoL was not significantly different from that of those who were not frail. There may be a number of explanations for these findings. First, it may imply that frail survivors adapt with time to their new vocation and/or disposition, despite the high prevalence of residual "problems." Second, this substudy may have had limited capability to detect significant clinical differences in HRQoL due to being relative small and within the context of the operative features of the EQ-5D. Regardless, this also translated into greater rates of rehospitalization in the subsequent 1-year period, implying greater health service use and healthcare costs for those screened as frail [5].

\section{Implications for clinicians and future research}

Our study has relevance for intensivists and all the other clinicians who care for survivors of critical illness. It also reinforces the potential value of frailty screening among selected younger patients admitted to the ICU. Recognition and acknowledgement of prehospital frailty can serve to inform survivorship expectations after critical illness, as well as steer the mobilization of customized recovery needs, both in the hospital and in the community, across physical, emotional, and social domains [41]. The ideal content and implementation of multifactorial, interprofessional post-ICU interventions to improve recovery remain uncertain and a challenge for providers $[42,43]$. Importantly, we believe further rigorous research in larger cohorts is needed to confirm our findings, to further characterize those younger patients most likely to benefit from frailty screening, and to develop translatable interventions aimed at enhancing recovery (i.e., preserving autonomy, slowing health status deterioration, societal reintegration and engagement) and informing clinical decision-making [13]. Moreover, future work should ideally evaluate the comparative performance of additional screening instruments in addition to the CFS score (e.g., frailty index, physical performance measures). In addition, one of the most important implications of our work is that future research related to recognizing and mitigating frailty should not necessarily be age-restricted. Indeed, on the basis of the importance of prior hospitalizations and the presence of selected comorbid conditions, we believe that the cohort of younger frail patients is only likely to increase over time.

\section{Limitations}

Our study has important limitations that must be considered. First, while the study was preplanned, we recognize that it entails a secondary analysis focused on a smaller subgroup with limited statistical power. Second, while this study was focused on younger critically ill patients, the age range for this subgroup was still limited to patients aged 50-64.9 years. We therefore cannot comment on the prevalence or implications of frailty among those younger than 50 years old. Third, we recognize that our study is susceptible to selection bias, given that all participants were recruited following ICU admission. Fourth, the CFS score was intended as a screening tool for frailty that was previously validated in older patients. We recognize there is no "gold standard" for the diagnosis of frailty among younger patients; however, we believe that the CFS is simple, has face validity, and was able to discriminate a subgroup at increased risk for adverse outcomes [6, 9]. We also did not capture additional highly correlated surrogates for frailty, such as sarcopenia, that were shown to have similar predictive capacity as measures of frailty 
for adverse outcomes among critically ill surgical patients [44]. Finally, as previously described [13], we did not capture physical performance measures such as mobility, grip strength, or cognition before critical illness, which may have particular relevance among younger frail survivors of critical illness.

\section{Conclusions}

Frailty is common among younger critically ill patients and predicts higher mortality, rates of rehospitalization at 1 year among those who survive critical illness. Frailty needs to be recognized and integrated into management of selected younger patients admitted to the ICU, and not just the elderly. A better understanding of the implications and outcomes associated with prehospital frailty among younger critically ill patients will inform prognostication; contribute to better-informed decisionmaking; help to manage the survivorship expectations for both patients and their families; and, importantly, guide innovative research focused on interventions.

\section{Key messages}

- Frailty was common among younger ICU patients, being present in an estimated one-fourth of those aged 50-64.9 years.

- Frail patients aged 50-64.9 years were more likely to be female, to have greater comorbid illness (in particular connective tissue disease), and to have impaired baseline function and disability.

- Frail patients aged 50-64.9 years were more likely to have been hospitalized in the 1-year period preceding ICU admission.

- Frail patients aged 50-64.9 years had higher adjusted mortality at 1 year and greater use of healthcare services.

\section{Additional files}

Additional file 1: Summary of participant flow in the study. (TIF $171 \mathrm{~kb}$ )

Additional file 2: Comparison of baseline sociodemographic, clinical, and comorbidity data for patients in the full study cohort and the subgroup aged $<65$ years old admitted to the ICU, stratified by frailty status. (DOCX $22 \mathrm{~kb}$ )

Additional file 3: Multivariable Cox proportional hazards model HR for death in the complete study cohort $(n=421)$. (DOCX $18 \mathrm{~kb})$

\section{Abbreviations}

APACHE, Acute Physiology and Chronic Health Evaluation; CFS, Clinical Frailty Scale; CSHA, Canadian Study on Health and Aging; CTD, connective tissue disease; DNR, do not resuscitate; ED, emergency department; EQ-5D, EuroQol Health Questionnaire; HF, heart failure; HRQOL, health-related quality of life; $I C U$, intensive care unit; IQR, interquartile range; MCID, minimal clinically important difference; SOFA, Sequential Organ Failure Assessment; VAS, visual analogue scale
}

\section{Acknowledgements}

The following are the participating centers and investigators of this study: Edmonton sites: University of Alberta Hospital: Sean M. Bagshaw, Robert C. McDermid, Darryl Rolfson, Ross Tsuyuki, Nadia Baig, Quazi Ibrahim, and Sumit R. Majumdar; Grey Nuns Community Hospital: Daniel E. Stollery; Misericordia Community Hospital: Ella Rokosh

Calgary Sites: Foothills Medical Centre: H. Thomas Stelfox; Rockyview General Hospital: George Alvarez; Peter Lougheed Hospital: Luc Berthiaume The authors acknowledge the coordinators whose work was essential to completion of this study: Nadia Baig, Barbara Artiuch, Tracy Davyduke, Maliha Muneer, Kristen Reid, Gwen Thompson, Robin Scheelar, Jennifer Barchard, and Samantha Taylor.

\section{Funding}

This work was supported by grants from the Canadian Intensive Care Foundation, the University Hospital Foundation, and the Canadian Institutes of Health Research. The funding agencies had no role in the design or conduct of the study; in the collection, management, analysis, or interpretation of the data; or in the preparation, review, or approval of the manuscript.

\section{Authors' contributions}

Study design and conception: SMB, HTS, DBR, and SRM. Data acquisition, analysis, and interpretation: SMB, HTS, QI, DBR, and SRM. Manuscript writing, critical revision, and final approval: all authors.

\section{Authors' information}

SMB holds a Canada research chair in critical care nephrology. HTS is supported by a Population Health Investigator Award from Alberta Innovates. RCM holds the Endowed Chair in Patient Health Management (supported by the Faculty of Medicine and Dentistry and the Faculty of Pharmacy and Pharmaceutical Sciences, University of Alberta).

\section{Competing interests}

The authors declare that they have no competing interests.

\section{Ethical approval and consent to participate}

The study was approved by the research ethics board at the University of Alberta (Pro00007628). All participants provided written informed consent to participate.

\section{Author details}

${ }^{1}$ Division of Critical Care Medicine (University of Alberta Hospital), Faculty of Medicine and Dentistry, University of Alberta, 2-124 Clinical Sciences Building, 8440-112 Street NW, Edmonton, AB T6G 2B7, Canada. ${ }^{2}$ Department of Medicine, Faculty of Medicine and Dentistry, University of Alberta, 5-112 Clinical Sciences Building, 8440-112 Street, Edmonton, AB T6G 2B7, Canada. ${ }^{3}$ Division of Geriatric Medicine, Department of Medicine, Faculty of Medicine and Dentistry, University of Alberta, 13-103 Clinical Sciences Building, 8440-112 Street, Edmonton, AB T6G 2B7, Canada. ${ }^{4}$ Population Health Research Institute, McMaster University, 237 Barton Street East, Hamilton, ON L8L 2X2, Canada. ${ }^{5}$ Department of Medicine, Faculty of Medicine and Dentistry, University of British Columbia, 317-2194 Health Sciences Mall, Vancouver, BC V6T 1Z3, Canada. 'Department of Critical Care Medicine, Faculty of Medicine, University of Calgary, 2500 University Drive NW, Calgary, AB T2N 1N4, Canada.

Received: 6 March 2016 Accepted: 12 May 2016

Published online: 06 June 2016

\section{References}

1. Fried LP, Ferrucci L, Darer J, Williamson JD, Anderson G. Untangling the concepts of disability, frailty, and comorbidity: implications for improved targeting and care. J Gerontol A Biol Sci Med Sci. 2004;59(3):255-63.

2. Mitnitski AB, Graham JE, Mogilner AJ, Rockwood K. Frailty, fitness and late-life mortality in relation to chronological and biological age. BMC Geriatr. 2002;2:1.

3. Rockwood K, Howlett SE, MacKnight C, Beattie BL, Bergman H, Hebert R, et al. Prevalence, attributes, and outcomes of fitness and frailty in communitydwelling older adults: report from the Canadian Study of Health and Aging. J Gerontol A Biol Sci Med Sci. 2004;59(12):1310-7. 
4. Gill TM, Gahbauer EA, Han L, Allore HG. Trajectories of disability in the last year of life. N Engl J Med. 2010;362(13):1173-80.

5. Fassbender K, Fainsinger RL, Carson M, Finegan BA. Cost trajectories at the end of life: the Canadian experience. J Pain Symptom Manage. 2009;38(1):75-80.

6. Rockwood K, Song X, MacKnight C, Bergman H, Hogan DB, McDowell I, et al. A global clinical measure of fitness and frailty in elderly people. CMAJ. 2005;173(5):489-95.

7. Dasgupta M, Rolfson DB, Stolee P, Borrie MJ, Speechley M. Frailty is associated with postoperative complications in older adults with medical problems. Arch Gerontol Geriatr. 2009;48(1):78-83.

8. Makary MA, Segev DL, Pronovost PJ, Syin D, Bandeen-Roche K, Patel P, et al. Frailty as a predictor of surgical outcomes in older patients. J Am Coll Surg. 2010;210(6):901-8.

9. Sundermann S, Dademasch A, Praetorius J, Kempfert J, Dewey T, Falk V, et al. Comprehensive assessment of frailty for elderly high-risk patients undergoing cardiac surgery. Eur J Cardiothorac Surg. 2011;39(1):33-7.

10. Bilotta C, Bowling A, Casè A, Nicolini P, Mauri S, Castelli $M$, et al. Dimensions and correlates of quality of life according to frailty status: a cross-sectional study on community-dwelling older adults referred to an outpatient geriatric service in Italy. Health Qual Life Outcomes. 2010;8:56.

11. Bagshaw SM, Stelfox HT, McDermid RC, Rolfson DB, Tsuyuki RT, Baig N, et al. Association between frailty and short- and long-term outcomes among critically ill patients: a multicentre prospective cohort study. CMAJ. 2014;186(2):E95-102

12. Le Maguet P, Roquilly A, Lasocki S, Asehnoune K, Carise E, Saint Martin M, et al. Prevalence and impact of frailty on mortality in elderly ICU patients: a prospective, multicenter, observational study. Intensive Care Med. 2014:40(5):674-82

13. Bagshaw SM, Stelfox HT, Johnson JA, McDermid RC, Rolfson DB, Tsuyuki RT, et al. Long-term association between frailty and health-related quality of life among survivors of critical illness: a prospective multicenter cohort study. Crit Care Med. 2015;43(5):973-82.

14. Baldwin MR, Narain WR, Wunsch H, Schluger NW, Cooke JT, Maurer MS, et al. A prognostic model for 6-month mortality in elderly survivors of critical illness. Chest. 2013;143(4):910-9.

15. Hope AA, Gong MN, Guerra C, Wunsch H. Frailty before critical illness and mortality for elderly Medicare beneficiaries. J Am Geriatr Soc. 2015;63(6):1121-8.

16. Heyland DK, Garland A, Bagshaw SM, Cook D, Rockwood K, Stelfox HT, et al. Recovery after critical illness in patients aged 80 years or older: a multicenter prospective observational cohort study. Intensive Care Med. 2015:41(11):1911-20

17. Rockwood K, Song X, Mitnitski A. Changes in relative fitness and frailty across the adult lifespan: evidence from the Canadian National Population Health Survey. CMAJ. 2011;183(8):E487-94

18. Elixhauser A, Steiner C, Harris DR, Coffey RM. Comorbidity measures for use with administrative data. Med Care. 1998;36(1):8-27.

19. Knaus WA, Draper EA, Wagner DP, Zimmerman JE. APACHE II: a severity of disease classification system. Crit Care Med. 1985;13(10):818-29.

20. Vincent JL, Moreno R, Takala J, Willatts S, De Mendonça A, Bruining H, et al. The SOFA (Sepsis-related Organ Failure Assessment) score to describe organ dysfunction/failure. On behalf of the Working Group on Sepsis-Related Problems of the European Society of Intensive Care Medicine. Intensive Care Med. 1996;22(7):707-10.

21. Harrell Jr FE. Overview of maximum likelihood estimation. In: Regression modeling strategies: with applications to linear models, logistic regression, and survival analysis. 1st ed. New York: Springer-Verlag; 2001. p. 179-214.

22. Fisher C, Karalapillai DK, Bailey M, Glassford NG, Bellomo R, Jones D. Predicting intensive care and hospital outcome with the Dalhousie Clinical Frailty Scale: a pilot assessment. Anaesth Intensive Care. 2015;43(3):361-8.

23. Singer JP, Diamond JM, Gries CJ, McDonnough J, Blanc PD, Shah R, et al Frailty phenotypes, disability, and outcomes in adult candidates for lung transplantation. Am J Respir Crit Care Med. 2015;192(11):1325-34.

24. Cron DC, Friedman JF, Winder GS, Thelen AE, Derck JE, Fakhoury JW, et al. Depression and frailty in patients with end-stage liver disease referred for transplant evaluation. Am J Transplant. 2015. doi:10.1111/ajt.13639.

25. McAdams-DeMarco MA, Tan J, Salter ML, Gross A, Meoni LA, Jaar BG, et al. Frailty and cognitive function in incident hemodialysis patients. Clin J Am Soc Nephrol. 2015;10(12):2181-9.

26. McAdams-DeMarco MA, Law A, King E, Orandi B, Salter M, Gupta N, et al. Frailty and mortality in kidney transplant recipients. Am J Transplant. 2015;15(1):149-54.
27. Bagshaw SM, McDermid RC. The role of frailty in outcomes from critical illness. Curr Opin Crit Care. 2013;19(5):496-503.

28. Mitnitski A, Rockwood $K$. The rate of aging: the rate of deficit accumulation does not change over the adult life span. Biogerontology. 2016;17(1):199-204.

29. Lone NI, Seretny M, Wild SH, Rowan KM, Murray GD, Walsh TS. Surviving intensive care: a systematic review of healthcare resource use after hospital discharge*. Crit Care Med. 2013;41(8):1832-43.

30. Myhren $\mathrm{H}$, Ekeberg $\mathrm{O}$, Stokland $\mathrm{O}$. Health-related quality of life and return to work after critical illness in general intensive care unit patients: a 1-year follow-up study. Crit Care Med. 2010;38(7):1554-61.

31. Myhren H, Ekeberg O, Tøien K, Karlsson S, Stokland O. Posttraumatic stress, anxiety and depression symptoms in patients during the first year post intensive care unit discharge. Crit Care. 2010;14(1):R14.

32. Pandharipande PP, Girard TD, Jackson JC, Morandi A, Thompson JL, Pun BT, et al. Long-term cognitive impairment after critical illness. N Engl J Med. 2013;369(14):1306-16.

33. Rockwood MR, MacDonald E, Sutton E, Rockwood K, Baron M, Canadian Scleroderma Research Group. Frailty index to measure health status in people with systemic sclerosis. J Rheumatol. 2014;41(4):698-705.

34. Hurtado-Torres GF, González-Baranda LL, Abud-Mendoza C. Rheumatoid cachexia and other nutritional alterations in rheumatologic diseases. Reumatol Clin. 2015;11(5):316-21

35. Puthucheary ZA, Rawal J, McPhail M, Connolly B, Ratnayake G, Chan P, et al. Acute skeletal muscle wasting in critical illness. JAMA. 2013;310(15):1591-600.

36. Weijs PJ, Looijaard WG, Dekker IM, Stapel SN, Girbes AR, Oudemans-van Straaten HM, et al. Low skeletal muscle area is a risk factor for mortality in mechanically ventilated critically ill patients. Crit Care. 2014;18(1):R12.

37. Jha SR, Ha HS, Hickman LD, Hannu M, Davidson PM, Macdonald PS, et al. Frailty in advanced heart failure: a systematic review. Heart Fail Rev. 2015;20(5):553-60

38. Uchmanowicz I, Gobbens RJ. The relationship between frailty, anxiety and depression, and health-related quality of life in elderly patients with heart failure. Clin Interv Aging. 2015;10:1595-600.

39. Griffiths J, Hatch RA, Bishop J, Morgan K, Jenkinson C, Cuthbertson BH, et al. An exploration of social and economic outcome and associated healthrelated quality of life after critical illness in general intensive care unit survivors: a 12-month follow-up study. Crit Care. 2013;17(3):R100.

40. Jackson JC, Pandharipande PP, Girard TD, Brummel NE, Thompson JL, Hughes CG, et al. Depression, post-traumatic stress disorder, and functional disability in survivors of critical illness in the BRAIN-ICU study: a longitudinal cohort study. Lancet Respir Med. 2014;2(5):369-79.

41. Gobbens RJ, van Assen MA. The prediction of quality of life by physical, psychological and social components of frailty in community-dwelling older people. Qual Life Res. 2014;23(8):2289-300.

42. Mehlhorn J, Freytag A, Schmidt K, Brunkhorst FM, Graf J, Troitzsch U, et al. Rehabilitation interventions for postintensive care syndrome: a systematic review. Crit Care Med. 2014;42(5):1263-71.

43. Walsh TS, Salisbury LG, Merriweather JL, Boyd JA, Griffith DM, Huby G, et al. Increased hospital-based physical rehabilitation and information provision after intensive care unit discharge: the RECOVER randomized clinical trial. JAMA Intern Med. 2015;175(6):901-10.

44. Mueller N, Murthy S, Tainter CR, Lee J, Riddell K, Fintelmann FJ, et al. Can sarcopenia quantified by ultrasound of the rectus femoris muscle predict adverse outcome of surgical intensive care unit patients as well as frailty? A prospective, observational cohort study. Ann Surg. 2015. doi:10.1097/SLA.0000000000001546. 